\title{
Retinoic Acid Induced Protein 14 (Rai14) is dispensable for mouse spermatogenesis
}

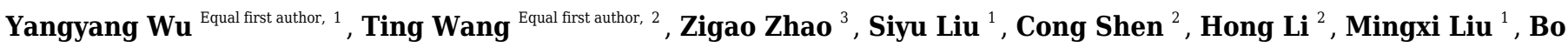 \\ Zheng ${ }^{\text {Corresp., } 2}$, Jun Yu ${ }^{4}$, Xiaoyan Huang ${ }^{\text {corresp. } 1}$ \\ ${ }^{1}$ State Key Laboratory of Reproductive Medicine, Department of Histology and Embryology, Nanjing Medical University, Nanjing, China \\ 2 Center for Reproduction and Genetics, Suzhou Municipal Hospital[the Affiliated Suzhou Hospital of Nanjing Medical University, Suzhou, China \\ ${ }^{3}$ Yunnan Institute of Population and Family Planning Science and Technology, Kunming, China \\ 4 Institute of Reproductive Medicine $\square$ Medical School, Nantong University, Nantong, China \\ Corresponding Authors: Bo Zheng, Xiaoyan Huang \\ Email address: mansnoopy@163.com, bbhxy@njmu.edu.cn
}

Background: Retinoic Acid Induced Protein 14 (Rai14) is an evolutionarily conserved gene that is highly expressed in the testis. Previous experiments have reported that small interfering RNA (siRNA)-mediated gene knockdown (KD) of Rail4 in rat testis disrupted spermatid polarity and transport. Of note, a gene knockout (KO) model is considered the "gold standard" for in vivo assessment of crucial gene functions. Herein, we used CRISPR/Cas9-based gene editing to investigate the in vivo role of Rai14 in mouse testis. Methods: Sperm concentration and motility were assayed using a computer-assisted sperm analysis (CASA) system. Histological and immunofluorescence (IF) staining and transmission electron microscopy (TEM) were used to visualize the effects of Rai14 KO in the testes and epididymides. Terminal deoxynucleotidyl transferase-dUTP nick-end labeling (TUNEL) was used to determine apoptotic cells. Gene transcript levels were calculated by real-time quantitative PCR. Results: Rai14 KO in mice depicted normal fertility and complete spermatogenesis, which is in sharp contrast with the results reported previously in a Rai14 KD rat model. Sperm parameters and cellular apoptosis did not appear to differ between wild-type (WT) and KO group. Mechanistically, in contrast to the well-known role of Rai14 in modulating the dynamics of F-actin at the ectoplasmic specialization (ES) junction in the testis, morphological changes of ES junction exhibited no differences between Rai14 KO and WT testes. Moreover, the F-actin surrounded at the ES junction was also comparable between the two groups. Conclusion: In summary, our study demonstrates that Rai14 is dispensable for mouse spermatogenesis and fertility. Although the results of this study were negative, the phenotypic information obtained herein provide an enhanced understanding of the role of Rai14 in the testis, and researchers may refer to these results to avoid conducting redundant experiments. 
1 Retinoic Acid Induced Protein 14 (Rai14) is dispensable for mouse spermatogenesis

2

3 Yangyang $\mathrm{Wu}^{1, *}$, Ting Wang ${ }^{3, *}$, Zigao Zhao ${ }^{4, *}$, Siyu Liu ${ }^{1}$, Cong Shen ${ }^{3}$, Hong $\mathrm{Li}^{3}$, Mingxi Liu ${ }^{1}$,

4 Bo Zheng ${ }^{3}$, Jun $\mathrm{Yu}^{2, *}$ and Xiaoyan Huang ${ }^{1}$

5

61 State Key Laboratory of Reproductive Medicine, Department of Histology and Embryology,

$7 \quad$ Nanjing Medical University, Nanjing, China

82 Institute of Reproductive Medicine, Medical School, Nantong University, Nantong, China

93 Center for Reproduction and Genetics, Suzhou Municipal Hospital, the Affiliated Suzhou

10 Hospital of Nanjing Medical University, Suzhou, China

114 Yunnan Institute of Population and Family Planning Science and Technology, Kunming, China

$14 *$ These authors contributed equally to this work.

16 Corresponding author

17 Bo Zheng, mansnoopy@163.com,

18 Xiaoyan Huang, bbhxy@,njmu.edu.cn

21 ABSTRACT 
22 Background: Retinoic Acid Induced Protein 14 (Rai14) is an evolutionarily conserved gene that

23 is highly expressed in the testis. Previous experiments have reported that small interfering RNA

24 (siRNA)-mediated gene knockdown (KD) of Rail4 in rat testis disrupted spermatid polarity and

transport. Of note, a gene knockout $(\mathrm{KO})$ model is considered the "gold standard" for in vivo assessment of crucial gene functions. Herein, we used CRISPR/Cas9-based gene editing to investigate the in vivo role of Rail4 in mouse testis.

Methods: Sperm concentration and motility were assayed using a computer-assisted sperm analysis (CASA) system. Histological and immunofluorescence (IF) staining and transmission electron microscopy (TEM) were used to visualize the effects of Rai14 $\mathrm{KO}$ in the testes and epididymides. Terminal deoxynucleotidyl transferase-dUTP nick-end labeling (TUNEL) was used to determine apoptotic cells. Gene transcript levels were calculated by real-time quantitative PCR.

Results: Rail4 KO in mice depicted normal fertility and complete spermatogenesis, which is in sharp contrast with the results reported previously in a Rail4 KD rat model. Sperm parameters and cellular apoptosis did not appear to differ between wild-type (WT) and KO group. Mechanistically, in contrast to the well-known role of Rail4 in modulating the dynamics of Factin at the ectoplasmic specialization (ES) junction in the testis, morphological changes of ES junction exhibited no differences between Rail4 KO and WT testes. Moreover, the F-actin surrounded at the ES junction was also comparable between the two groups. 
44 Conclusion: In summary, our study demonstrates that Rail4 is dispensable for mouse 45 spermatogenesis and fertility. Although the results of this study were negative, the phenotypic 46 information obtained herein provide an enhanced understanding of the role of Rail4 in the testis, 47 and researchers may refer to these results to avoid conducting redundant experiments.

INTRODUCTION

63 Spermatogenesis is a complex process of germ cell proliferation and differentiation, and is 
64

65

66

67

68

69

associated with the extensive restructuring of cell junctions at the Sertoli-Sertoli cell and Sertoligerm cell interfaces (Upadhyay et al. 2012). Of the various junctions in the seminiferous epithelium, the ectoplasmic specialization (ES) junction is a testis-specific adherens junction. It is an atypical actin-based junction at the blood-testis barrier (BTB) between adjacent Sertoli cells and is referred to as the basal ES, and between Sertoli cell and spermatid near the luminal surface of the seminiferous epithelium and is termed as the apical ES (Cheng \& Mruk 2010). The ES junction consists of hexagonal bundles of actin filaments sandwiched between cisternae of the endoplasmic reticulum and the plasma membranes (Lee \& Cheng 2004). During spermatogenesis, the ES primarily facilitates germ cell transport, polarity, and spermiation (Qian et al. 2014).

The Retinoic Acid Induced Protein 14 (RAI14) gene is a developmentally regulated gene that is induced by retinoic acid. RAII4 was originally identified in human retinal pigment epithelial cells (Kutty et al. 2001). In human tissues, RAII4 is predominantly expressed in the placenta and testes (Kutty et al. 2006a). The RAI14 protein comprises six ankyrin repeats and a long coiledcoil domain near the $\mathrm{N}$-terminal region and the $\mathrm{C}$-terminus, respectively. These domains are involved in protein-protein interactions (Kutty et al. 2006b). Qian et al. demonstrated that RAI14 is expressed at both the Sertoli and germ cells in rat testes (Qian et al. 2013b). They also demonstrated specific distribution of RAI14 at both the basal ES and the apical ES in rat testes. They found that RAI1 regulated F-actin organization at the ES. In another study, Qian et al. found that small interfering RNA (siRNA)-mediated Rail4 KD in Sertoli cells disturbed the 
85

86

87

88

89

permeability of the cell junction as well as disrupted F-actin in vitro. Moreover, siRNA-mediated Rail4 KD in rat testis in vivo disrupted spermatid polarity and adhesion as well as spermatid movement, which were caused by the disruption of the apical ES (Qian et al. 2013a).

RAI14 has also been found to be predominantly expressed in mouse testis (Kutty et al. 2006b).

However, little is known about its function during mouse spermatogenesis. In the present study, we aimed to uncover the physiological role of RAI14 in mouse testis through CRISPR/Cas9based gene editing.

\section{MATERIALS AND METHODS}

\section{Mice}

CD-1 mice were obtained and maintained in a temperature and humidity- controlled room at the Experimental Animal Center of Nanjing Medical University with food and water provided ad libitum. Mice were randomly divided into cages. All individualized ventilated cages were capable of hosting 4-5 mice. Cages density, bedding, and sanitation frequency was similar in all cages. At the end of the study, mice were anesthetized with carbon dioxide. This study was carried out in strict accordance with the guidelines of the Institutional Animal Care and Use Committee of Nanjing Medical University (China). Animal use was approved by the Animal Ethical and Welfare Committee (AEWC) of Nanjing Medical University (Permit Number: IACUC-2004020). For the generation of Rail4 KO mice, Cas9 plasmid (Addgene, Watertown, MA, USA) was linearized and transcribed into mRNA in vitro using a T7 Transcription Kit 
106 (Ambion, Austin, TX, USA). The sgRNAs were designed based on exon 3 of Rail4. The target

107 sgRNA sequence was 5'- CCGTCTGCTGCAGGCTGTGGAGA $\quad-3^{\prime}$ and 5'108 GAGAAGGTGGCCTCACTGCTGGG -3', respectively. Cas9 mRNA and sgRNA were 109 microinjected into CD-1 mouse zygotes and transferred into the oviducts of pseudopregnant CD1101 females. The Rail4 genotype was verified by PCR amplification (Vazyme, Nanjing, China) 111 using the following primers: (forward 5'- GGAGTTTGCTGATGGCTGGTATT -3' and reverse 5'- CTCCATCGCCAACACTGTAAGAA -3').

\section{Western blot}

Western blot analysis was performed according to our previously reported method with minor modifications (Shen et al. 2019; Zheng et al. 2018). Briefly, testis lysates were separated through electrophoresis and electro-transferred to polyvinylidene difluoride (PVDF) membranes (BioRad, Hercules, USA). The PVDF membranes were blocked with 5\% nonfat milk for 2 hours at room temperature (RT) and incubated overnight at $4^{\circ} \mathrm{C}$ with the primary antibodies: anti-RAI14 rabbit antibody (17507-1-AP; Proteintech, Chicago, IL, USA) at a dilution of 1:2,000 and antiTubulin mouse antibody (AT819; Beytime, Nantong, China) at a dilution of 1:20,000. Blots were then washed and incubated at RT for 2 hours with horseradish peroxidase- conjugated secondary antibodies at a dilution of 1:2,000 (Thermo Scientific, Waltham, USA). The signals were visualized using enhanced chemiluminescent (Thermo Scientific, Waltham, USA). 
127 Testes were dissected and fixed in modified Davidson's fluid (MDF) for at least 48 hours before

128 being embedded in paraffin. The sections were deparaffinized in xylene, hydrated in graded

129 ethanol and boiled in sodium citrate buffer for antigen retrieval as previously described (Shen et

130 al. 2018; Zhao et al. 2019). Sections were then blocked with 1\% bovine serum albumin at RT for

1312 hours and incubated overnight at $4^{\circ} \mathrm{C}$ with the primary antibodies: anti-RAI14 rabbit antibody

132 (17507-1-AP; Proteintech, Chicago, IL, USA) at a dilution of 1:200, anti-Lin28 rabbit antibody

133 (ab46020; Abcam, Cambridge, MA, USA) at a dilution of 1:500, anti- $\gamma \mathrm{H} 2 \mathrm{AX}$ mouse antibody

134 (ab26350; Abcam, Cambridge, MA, USA) at a dilution of 1:1000, anti-Vimentin mouse antibody

135 (sc-6260; Santa Cruz Biotechnology, Santa Cruz, CA, USA) at a dilution of 1:200, anti- HSD-3 $\beta$

136 (sc-515120; Santa Cruz Biotechnology, Santa Cruz, CA, USA) at a dilution of 1:500, anti- $\beta$ -

137 catenin mouse antibody (610153; BD Sciences, Franklin Lakes, NJ, USA) at a dilution of 1:200,

138 anti-Espin (611656; BD Sciences, Franklin Lakes, NJ, USA) at a dilution of 1:300 and anti-

139 Palladin rabbit antibody (10853-1-AP; Proteintech, Chicago, IL, USA) at a dilution of 1:400.

140 Slides were rinsed before incubation with Alexa-Fluor secondary antibodies (Thermo Scientific,

141 Waltham, USA) for $1 \mathrm{~h}$ at $37^{\circ} \mathrm{C}$. Finally, the slides were stained with Hoechst (Invitrogen,

142 Carlsbad, CA, USA) and images were captured using a confocal microscope (Zeiss LSM800,

143 Carl Zeiss, Oberkochen, Germany).

145 Fertility test

146 Adult males of Rail4 wild-type (WT, +/+) and knockout (KO, -/-) were housed individually with

147 two WT CD-1 females for 16 weeks. The numbers of vaginal plugs and pups were counted, and 
148 the dates of birth were recorded in detail for each litter.

149

150 Computer-assisted sperm analysis (CASA)

151 Sperm were collected from the cauda epididymis and suspended in human tubal fluid and

152 maintained at $37^{\circ} \mathrm{C}$. Sperm samples were then diluted, placed on an $80-\mu \mathrm{m}$ chamber slide, and

153 analyzed using Oval Head Toxicology software and the Hamilton Thorne's Ceros II analyzer

154 (Beverly, MA, USA). The parameters analyzed included sperm concentration and motility.

155

156

\section{Histological analysis}

157 The testes and epididymides were obtained from Rail4 WT and KO mice, fixed in MDF for at 158 least 48 hours, dehydrated in graded ethanol, embedded in paraffin, and finally sectioned into 5$\mu \mathrm{m}$ thickness. After deparaffinization, the epididymis and testis slides were stained with hematoxylin and eosin (HE) and periodic acid Schiff (PAS) reagent, respectively. For electron microscopy analysis, testis and sperm were fixed in 4\% and 2\% glutaraldehyde, respectively. The samples were embedded in araldite and sectioned into $80-\mathrm{nm}$ thickness. Images were examined under a transmission electron microscope (JEM-1010, JEOL).

Terminal deoxynucleotidyl transferase-dUTP nick-end labeling (TUNEL)

Apoptotic cells were identified using a TUNEL BrightRed Apoptosis Detection Kit (Vazyme,

Nanjing, China), as described in our previous study (Gao et al. 2020). In short, sections were deparaffinized, rehydrated, and incubated with proteinase $\mathrm{K}$ for $20 \mathrm{~min}$ at RT. The slides were 
169

170

171

172

173

174

175

176

177

178

179

180

181

182

183

184

185

186

187

188

189

then treated with equilibration buffer for 1 hour before labeling with BrightRed Labeling Buffer for 1 hour at $37^{\circ} \mathrm{C}$. The sections were then washed twice with phosphate-buffered saline (PBS), and stained with Hoechst for 5 minutes at RT to prepare mounting.

\section{RNA extraction and Real-time quantitative PCR}

Total RNA was extracted from the testicular tissues using TRIzol reagent (Vazyme, Nanjing, China), according to the manufacturer's instructions. RNA was reverse-transcribed into cDNA using a PrimeScript Reverse Transcription Mix (Vazyme, Nanjing, China). Thereafter, cDNA was then analyzed by SYBR Green-based real-time quantitative PCR in an Applied Biosystems 7500 real-time PCR system (Applied Biosystems, Foster City, CA, USA) with $18 S r R N A$ as an internal control. The primers used are as follows: $\beta$-catenin, forward 5'GGCGGCCGCGAGGTA -3' and reverse 5'- GTGGCTGACAGCAGCTTTTC -3'; Espin, forward 5'- CTTTGGAGCTGGGCAGTTGA $-3^{\prime}$ and reverse 5'TtgaAagAttgGtgCtGGGT $\quad-3^{\prime} ; \quad$ Palladin, forward 5'GCTGGATGTCTACATTTCCCGA -3' and reverse 5'-CCAGCCAGCCTAAGAAACCA -3'; 18sRNA, forward 5'- AAACGGCTACCACATCCAAG $-3^{\prime}$ and reverse 5'CCTCCAATGGATCCTCGTTA -3'.

\section{Statistical analysis}

Data were presented as the means \pm SD from at least three replicates for each experiment. The differences between Rail4 WT and KO mice were calculated using unpaired Student's t-test 
190

191

192

193

194

195

196

197

198

199

200

201

202

203

204

205

206

207

208

209

210

with statistical significance set at a $\mathrm{p}$ value of $<0.05$. The differences among the WT, KO and heterozygous were calculated using one-way ANOVA significance set at a p value of $<0.05$.

Microsoft Excel or GraphPad Prism 6.0 software were used for the statistical analyses.

\section{RESULTS}

\section{Generation of Rai14 KO mice}

To investigate the physiological function of Rail4, we generated Rail4 global KO mice using CRISPR/Cas9 technology. Two gRNAs were designed to target gene sites in exon 3 of the Rail4 gene, resulting in a 56-bp deletion of exon 3 (Fig. 1A). PCR amplification was performed to rapidly identify the genotypes from Rail4 WT (+/+), KO (-/-), and heterozygous (+/-) mice (Fig. 1B). Furthermore, western blot and immunofluorescence analyses were carried out to evaluate the absence of RAI14 at the protein level (Figs. 1C and 1D). As shown in Fig. 1C, western blot analysis could not detect RAI14 or truncated RAI14 in Rai14-KO testis. Additionally, immunofluorescence staining showed specific distribution of RAI14 in the cytoplasm of elongating spermatids in Rail4 WT testis, whereas no such obvious signal was observed in spermatids of Rail4 KO testis (Fig. 1D). In one previous in vivo study in rats, RAI14 was found to be distributed at the ES junction in rat testis; however, in our study, RAI14 was not found at the ES junction in the testis of Rail4 WT mice (Fig. 1D).

\section{Normal fertility and sperm parameter in Rai14-KO mice}

Rail4 KO mice were viable and exhibited normal development. A 4-month-long fertility test 
211 revealed that Rail4 KO adult males had normal fertility (Fig. 2A). The testicular weight of Rai14

$212 \mathrm{KO}$ and WT mice were comparable (Figs. 2B and 2C). Moreover, Rail4 KO males exhibited

213 normal sperm concentration, motility, and morphology, compared with WT males (Figs. 2D-2H).

214

215 Complete spermatogenesis in Rai14 KO testis

216 Histological analysis of Rail4 WT and KO mice revealed that the morphology of the testis and 217 epididymis of Rai14 KO and WT male mice was indistinguishable from each other (Figs. 3A and 218 3B). Similar conclusions were drawn on the basis of the normal expression and counts of the 219 spermatogonial stem cell maker Lin28 (Rode et al. 2018) (Figs. 3C and 3D); the spermatocyte marker $\gamma \mathrm{H} 2 \mathrm{AX}$ (Wang et al. 2016) (Figs. 3E and 3F); Sertoli cell marker Vimentin (Alsemeh et al. 2020) (Figs. 3G and 3H); and the Leydig cell marker HSD-3 $\beta$ (Cen et al. 2020) (Figs. 3I and 3J). Moreover, based on the results of the TUNEL analysis in our study, the number of apoptotic cells showed no significant difference between the two groups (Figs. 3K and 3L). Altogether, our results strongly demonstrate that Rail4 is not essential for spermatogenesis or fertility in male 225 mice.

ES junction is not disturbed in Rai14-KO testis

As RAI14 showed highest localization at the ES junction in adult rat testis, and siRNA-mediated

Rail4 KD led to the mis-localization of ES-associated proteins (Qian et al. 2013a), we sought to assess the localization of basal ES ( $\beta$-catenin and Espin) and apical ES (Espin and Palladin) proteins (Mruk \& Cheng 2004; Qian et al. 2013b) in both Rail4 WT and KO testes. Both real- 
232 time quantitative PCR (Figs. 4A-4C) and immunofluorescence (Figs. 4D-4I) analyses revealed

233 no measurable alterations in the transcript or protein levels of ES-associated genes between the

234 two groups.

235

236

Rai14 is not required for $\mathbf{F}$-actin organization in mouse testis

237 As an actin-binding protein, RAI14 participates in F-actin organization at the ES junction in rat testis (Qian et al. 2013a). Here, we used phalloidin-labeled F-actin staining to observe actin filaments surrounding the heads of elongating spermatids. In both Rail4 WT and KO testes, the actin filament bundles were intact and organized so that they tightly surrounded the spermatid heads (Fig. 5A). Furthermore, transmission electron microscopy (TEM) of the apical ES was performed in both the groups to better visualize the actin bundle organization. Ultrastructurally, the apical ES junctions in both groups consisted of actin filaments bundles sandwiched between the cisternae of the endoplasmic reticulum and the apposed Sertoli-spermatid plasma membranes (Fig. 5B). These data indicate that Rail4 is not essential for the assembly of actin filaments at the apical ES in mouse testis.

\section{DISCUSSION}

249 Previous microarray analyses have identified over 2,300 genes that are enriched in male germ cells (Schultz et al. 2003). Thereafter, many studies have been performed to characterize testisenriched genes/proteins based on transcriptomics and proteomics (Bonilla \& Xu 2008; Clement et al. 2007; Djureinovic et al. 2014; Pineau et al. 2019; Uhlen et al. 2015). In addition to 
253 housekeeping genes, testis-enriched genes have, for a long time, been thought to play a crucial

254 role in spermatogenesis. However, using gene-KO approaches, Miyata et al. have revealed 54

255 testis-enriched genes that are dispensable for male fertility in mice (Miyata et al. 2016). Since

256 then, several studies have established a number of $\mathrm{KO}$ mice models without obvious fertility

257 phenotypes (Feng et al. 2018; Holcomb et al. 2020; Lu et al. 2019; Park et al. 2020; Wang et al.

258 2018a; Wang et al. 2018b; Zhang et al. 2019). Similarly, we used CRISPR/Cas9-based gene

259 editing in our study and identified Rai14, which was enriched in the testis and was dispensable

260 for spermatogenesis and fertility in mice. Considering these findings, we believed that the

phenotypic information obtained in our study can inform other researchers and prevent them

from conducting redundant experiments. Moreover, these results can serve as a basic resource

for genetics studies on human fertility.

RAI14 has been previously considered as an actin cytoskeleton-associated protein purified from

rat liver tissue (Peng et al. 2000). Several studies have revealed that RAI14 is expressed in

various tissues and cells, but is highly expressed in both human and mouse testes (Kutty et al.

2001; Kutty et al. 2006b; Yuan et al. 2005). In rat testis, RAI14 was found to be exclusively

located at the ES junction, most abundantly at the apical ES. SiRNA-based Rai14 KD in rat testis

led to defects in elongating spermatid polarity and transport, and finally caused spermiation

failure. Mechanistically, RAI14 physiologically interacts with actin and another actin cross-

linking protein, Palladin. As suggested in previous studies, the altered phenotype caused by the

loss of RAI14 may be associated with the mis-localization of F-actin and Palladin at the apical

ES (Qian et al. 2013a; Qian et al. 2013b). However, in this study, RAI14 distribution occurred 
274 specifically in the cytoplasm of elongating spermatids, but not at the ES. Meanwhile, RAI14

275 fluorescence signals were undetectable in Rai14 KO testis, further supporting the specificity of

276 the antibody against RAI14. Furthermore, Rail4 KO mice displayed normal spermatogenesis

277 and fertility. Histological analysis revealed no difference in the ES structure, actin filament

278 bundle organization, as well as ES associated protein distribution between the two groups. Thus,

279 the question of the reasons for the phenotypic differences in KD versus KO arises. In our opinion,

280 at least two possibilities contribute to them. First, the different distributions of RAI14 in rat and

281 mouse testis suggest that RAI14 plays different roles in various species. In addition, these

282 phenotypic differences could also be explained by functional compensation from paralogs in KO

283 model or off-target effects in KD.

284

285 CONCLUSIONS

286 In summary, we achieved Rail4 global KO mice by using Cas9/sgRNA-mediated gene editing.

287 Our results provide proof-of-principle evidence to show that Rail4 is neither required for the ES

288 junction nor spermatogenesis in mice.

289

290

291

292

293

294

Peer) reviewing PDF | (2020:09:53137:1:1:NEW 5 Dec 2020) 


\section{REFERENCES}

302

303

304

305

306

307

308

309

310

311

312

313

314

315

316

317

318

319

320

321

322

323

324

325

326

327

328
Alsemeh AE, Samak MA, and El-Fatah SSA. 2020. Therapeutic prospects of hydroxytyrosol on experimentally induced diabetic testicular damage: potential interplay with AMPK expression. Cell Tissue Res 380:173189. 10.1007/s00441-019-03143-2

10.1007/s00441-019-03143-2 [pii]

Bonilla $\mathrm{E}$, and $\mathrm{Xu} \mathrm{EY}$. 2008. Identification and characterization of novel mammalian spermatogenic genes conserved from fly to human. Mol Hum Reprod 14:137-142. 10.1093/molehr/gan002

gan002 [pii]

Cen C, Chen M, Zhou J, Zhang L, Duo S, Jiang L, Hou X, and Gao F. 2020. Inactivation of Wt1 causes pre-granulosa cell to steroidogenic cell transformation and defect of ovary developmentdagger. Biol Reprod 103:60-69. 10.1093/biolre/ioaa042

5818877 [pii]

Cheng CY, and Mruk DD. 2010. A local autocrine axis in the testes that regulates spermatogenesis. Nat Rev Endocrinol 6:380-395. 10.1038/nrendo.2010.71

nrendo.2010.71 [pii]

Clement TM, Anway MD, Uzumcu M, and Skinner MK. 2007. Regulation of the gonadal transcriptome during sex determination and testis morphogenesis: comparative candidate genes. Reproduction 134:455-472. $134 / 3 / 455$ [pii]

10.1530/REP-06-0341

Djureinovic D, Fagerberg L, Hallstrom B, Danielsson A, Lindskog C, Uhlen M, and Ponten F. 2014. The human testisspecific proteome defined by transcriptomics and antibody-based profiling. Mol Hum Reprod 20:476-488. 10.1093/molehr/gau018

gau018 [pii]

Feng J, Liang P, Chen Y, Zhang X, Songyang Z, Zheng H, Cao S, and Huang J. 2018. Testis-specific Lypd9 is dispensable for spermatogenesis in mouse. Mol Reprod Dev 85:87-89. 10.1002/mrd.22942

Gao T, Lin M, Shao B, Zhou Q, Wang Y, Chen X, Zhao D, Dai X, Shen C, Cheng H, Yang S, Li H, Zheng B, Zhong X, Yu J, Chen L, and Huang X. 2020. BMI1 promotes steroidogenesis through maintaining redox homeostasis in mouse MLTC-1 and primary Leydig cells. Cell Cycle 19:1884-1898. 10.1080/15384101.2020.1779471

Peer] reviewing PDF | (2020:09:53137:1:1:NEW 5 Dec 2020) 
329

330

331

332

333

334

335

336

337

338

339

340

341

342

343

344

345

346

347

348

349

350

351

352

353

354

355

356

357

358

359

360

361

362

363

364

365

366

367

368

369
Holcomb RJ, Oura S, Nozawa K, Kent K, Yu Z, Robertson MJ, Coarfa C, Matzuk MM, Ikawa M, and Garcia TX. 2020. The testis-specific serine proteases PRSS44, PRSS46, and PRSS54 are dispensable for male mouse fertilitydagger. Biol Reprod 102:84-91. 10.1093/biolre/ioz158

5546741 [pii]

Kutty RK, Chen S, Samuel W, Vijayasarathy C, Duncan T, Tsai JY, Fariss RN, Carper D, Jaworski C, and Wiggert B. 2006a. Cell density-dependent nuclear/cytoplasmic localization of NORPEG (RAI14) protein. Biochem Biophys Res Commun 345:1333-1341. S0006-291X(06)01033-3 [pii]

10.1016/j.bbrc.2006.04.184

Kutty RK, Kutty G, Samuel W, Duncan T, Bridges CC, El-Sherbeeny A, Nagineni CN, Smith SB, and Wiggert B. 2001. Molecular characterization and developmental expression of NORPEG, a novel gene induced by retinoic acid. J Biol Chem 276:2831-2840. 10.1074/jbc.M007421200

M007421200 [pii]

Kutty RK, Samuel W, Chen S, Vijayasarathy C, Dun Y, Mysona B, Wiggert B, and Smith SB. 2006b. Immunofluorescence analysis of the expression of Norpeg (Rai14) in retinal Muller and ganglion cells. Neurosci Lett 404:294-298. S0304-3940(06)00562-3 [pii]

10.1016/j.neulet.2006.06.006

Lee NP, and Cheng CY. 2004. Ectoplasmic specialization, a testis-specific cell-cell actin-based adherens junction type: is this a potential target for male contraceptive development? Hum Reprod Update 10:349-369. 10.1093/humupd/dmh026

dmh026 [pii]

Lu Y, Oura S, Matsumura T, Oji A, Sakurai N, Fujihara Y, Shimada K, Miyata H, Tobita T, Noda T, Castaneda JM, Kiyozumi D, Zhang Q, Larasati T, Young SAM, Kodani M, Huddleston CA, Robertson MJ, Coarfa C, Isotani A, Aitken RJ, Okabe M, Matzuk MM, Garcia TX, and Ikawa M. 2019. CRISPR/Cas9-mediated genome editing reveals 30 testis-enriched genes dispensable for male fertility in micedagger. Biol Reprod 101:501-511. 10.1093/biolre/ioz103

5519226 [pii]

Miyata H, Castaneda JM, Fujihara Y, Yu Z, Archambeault DR, Isotani A, Kiyozumi D, Kriseman ML, Mashiko D, Matsumura T, Matzuk RM, Mori M, Noda T, Oji A, Okabe M, Prunskaite-Hyyrylainen R, Ramirez-Solis R, Satouh Y, Zhang Q, Ikawa M, and Matzuk MM. 2016. Genome engineering uncovers 54 evolutionarily conserved and testis-enriched genes that are not required for male fertility in mice. Proc Natl Acad Sci U S A 113:7704-7710. 10.1073/pnas.1608458113

1608458113 [pii]

Mruk DD, and Cheng CY. 2004. Sertoli-Sertoli and Sertoli-germ cell interactions and their significance in germ cell movement in the seminiferous epithelium during spermatogenesis. Endocr Rev 25:747-806. 25/5/747 [pii]

10.1210/er.2003-0022

Park S, Shimada K, Fujihara Y, Xu Z, Larasati T, Pratiwi P, Matzuk RM, Devlin DJ, Yu Z, Garcia TX, Matzuk MM, and Ikawa M. 2020. CRISPR/Cas9-mediated genome-edited mice reveal 10 testis-enriched genes are dispensable for male fecundity. Biol Reprod 103:195-204. 10.1093/biolre/ioaa084

5843374 [pii]

Peng YF, Mandai K, Sakisaka T, Okabe N, Yamamoto Y, Yokoyama S, Mizoguchi A, Shiozaki H, Monden M, and Takai Y. 2000. Ankycorbin: a novel actin cytoskeleton-associated protein. Genes Cells 5:1001-1008. gtc381 [pii]

PeerJ reviewing PDF | (2020:09:53137:1:1:NEW 5 Dec 2020) 
10.1046/j.1365-2443.2000.00381.x

Pineau C, Hikmet F, Zhang C, Oksvold P, Chen S, Fagerberg L, Uhlen M, and Lindskog C. 2019. Cell Type-Specific Expression of Testis Elevated Genes Based on Transcriptomics and Antibody-Based Proteomics. J Proteome Res 18:4215-4230. 10.1021/acs.jproteome.9b00351

Qian X, Mruk DD, and Cheng CY. 2013a. Rai14 (retinoic acid induced protein 14) is involved in regulating $\mathrm{f}$-actin dynamics at the ectoplasmic specialization in the rat testis*. PLoS One 8:e60656. 10.1371/journal.pone.0060656

PONE-D-13-02641 [pii]

Qian X, Mruk DD, Cheng YH, and Cheng CY. 2013b. RAI14 (retinoic acid induced protein 14) is an F-actin regulator: Lesson from the testis. Spermatogenesis 3:e24824. 10.4161/spmg.24824

Views, Commentaries \& Opinions [pii]

Qian X, Mruk DD, Cheng YH, Tang El, Han D, Lee WM, Wong EW, and Cheng CY. 2014. Actin binding proteins, spermatid transport and spermiation. Semin Cell Dev Biol 30:75-85. 10.1016/j.semcdb.2014.04.018

S1084-9521(14)00089-5 [pii]

Rode K, Weider K, Damm OS, Wistuba J, Langeheine M, and Brehm R. 2018. Loss of connexin 43 in Sertoli cells provokes postnatal spermatogonial arrest, reduced germ cell numbers and impaired spermatogenesis. Reprod Biol 18:456-466. S1642-431X(17)30237-1 [pii]

10.1016/j.repbio.2018.08.001

Schultz N, Hamra FK, and Garbers DL. 2003. A multitude of genes expressed solely in meiotic or postmeiotic spermatogenic cells offers a myriad of contraceptive targets. Proc Natl Acad Sci U S A 100:12201-12206. 10.1073/pnas. 1635054100

1635054100 [pii]

Shen C, Yu J, Zhang X, Liu CC, Guo YS, Zhu JW, Zhang K, Yu Y, Gao TT, Yang SM, Li H, Zheng B, and Huang XY. 2019. Strawberry Notch 1 (SBNO1) promotes proliferation of spermatogonial stem cells via the noncanonical Wnt pathway in mice. Asian J Androl 21:345-350.10.4103/aja.aja_65_18

240738 [pii]

Shen C, Zhang K, Yu J, Guo Y, Gao T, Liu Y, Zhang X, Chen X, Yu Y, Cheng H, Zheng A, Li H, Huang X, Ding X, and Zheng B. 2018. Stromal interaction molecule 1 is required for neonatal testicular development in mice. Biochem Biophys Res Commun 504:909-915. S0006-291X(18)31962-4 [pii]

10.1016/j.bbrc.2018.09.044

Uhlen M, Fagerberg L, Hallstrom BM, Lindskog C, Oksvold P, Mardinoglu A, Sivertsson A, Kampf C, Sjostedt E, Asplund A, Olsson I, Edlund K, Lundberg E, Navani S, Szigyarto CA, Odeberg J, Djureinovic D, Takanen JO, Hober S, Alm T, Edqvist PH, Berling H, Tegel H, Mulder J, Rockberg J, Nilsson P, Schwenk JM, Hamsten M, von Feilitzen K, Forsberg M, Persson L, Johansson F, Zwahlen M, von Heijne G, Nielsen J, and Ponten F. 2015. Proteomics. Tissue-based map of the human proteome. Science 347:1260419. 10.1126/science.1260419

1260419 [pii]

347/6220/1260419 [pii]

Upadhyay RD, Kumar AV, Ganeshan M, and Balasinor NH. 2012. Tubulobulbar complex: cytoskeletal remodeling to release spermatozoa. Reprod Biol Endocrinol 10:27. 10.1186/1477-7827-10-27

1477-7827-10-27 [pii] 
411

412

413

414

415

416

417

418

419

420

421

422

423

424

425

426

427

428

429

430

431

432
Wang CY, Tang MC, Chang WC, Furushima K, Jang CW, Behringer RR, and Chen CM. 2016. PiggyBac TransposonMediated Mutagenesis in Rats Reveals a Crucial Role of Bbx in Growth and Male Fertility. Biol Reprod 95:51. 10.1095/biolreprod.116.141739

biolreprod.116.141739 [pii]

Wang YQ, Chen SR, and Liu YX. 2018a. Selective deletion of WLS in peritubular myoid cells does not affect spermatogenesis or fertility in mice. Mol Reprod Dev 85:559-561. 10.1002/mrd.22988

Wang Z, Lee S, Oliver D, Yuan S, Tang C, Wang Y, Zheng H, and Yan W. 2018b. Prps1l1, a testis-specific gene, is dispensable for mouse spermatogenesis. Mol Reprod Dev 85:802-804. 10.1002/mrd.23053

Yuan W, Zheng Y, Huo R, Lu L, Huang XY, Yin LL, Li JM, Zhou ZM, and Sha JH. 2005. Expression of a novel alternative transcript of the novel retinal pigment epithelial cell gene NORPEG in human testes. Asian J Androl 7:277288. 10.1111/j.1745-7262.2005.00040.x

Zhang J, Zhang X, Zhang Y, Zeng W, Zhao S, and Liu M. 2019. Normal spermatogenesis in Fank1 (fibronectin type 3 and ankyrin repeat domains 1) mutant mice. PeerJ 7:e6827. 10.7717/peerj.6827

6827 [pii]

Zhao D, Shen C, Gao T, Li H, Guo Y, Li F, Liu C, Liu Y, Chen X, Zhang X, Wu Y, Yu Y, Lin M, Yuan Y, Huang X, Yang S, Yu J, Zhang J, and Zheng B. 2019. Myotubularin related protein 7 is essential for the spermatogonial stem cell homeostasis via PI3K/AKT signaling. Cell Cycle 18:2800-2813. 10.1080/15384101.2019.1661174

Zheng B, Yu J, Guo Y, Gao T, Shen C, Zhang X, Li H, and Huang X. 2018. Cellular nucleic acid-binding protein is vital to testis development and spermatogenesis in mice. Reproduction 156:59-69. 10.1530/REP-17-0666

REP-17-0666 [pii] 
Figure 1

Generation of Rai14 ${ }^{-/}$mice.

(A) Schematic diagram of CRISPR/Cas9-mediated Rai14 editing; (B) PCR amplification of genomic DNA in Rai14 ${ }^{+/+},{ }^{-/}$and ${ }^{+/}$mice; (C) Western blot analysis of RAl14 in Rai14 ${ }^{+/+}$and ${ }^{-/}$ testes; (D) Co-immunostaining of RAl14 and PNA in Rai14 ${ }^{+/+}$and ${ }^{*}$ testes. The epithelial cycle is divided into 12 stages recognized by PNA-labeled acrosomes. RAl14 is specifically located in spermatids at steps 11-14. Rai14/ tubules are used as the negative control. Scale bar: 20 $\mu \mathrm{m}$. 


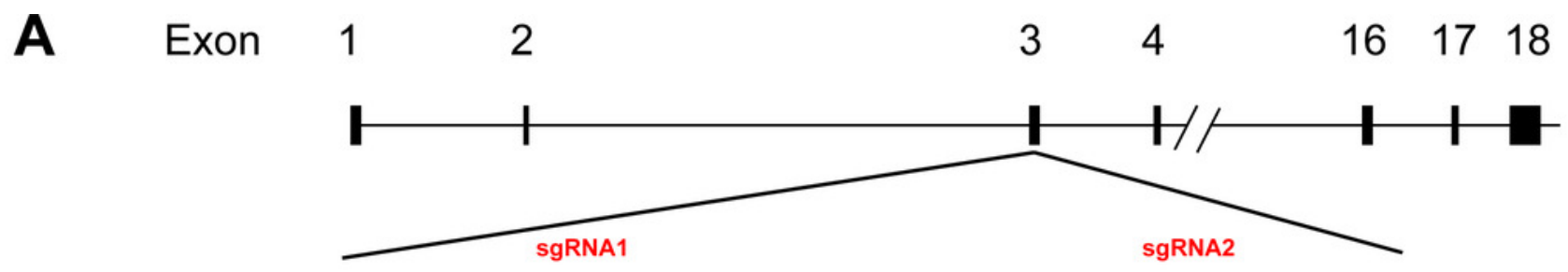

agaatgatgaccgtctgctgcaggctgtggagaacggagatgctgagaaggtggcctcactgctgggcaagaaaggg (WT)

B

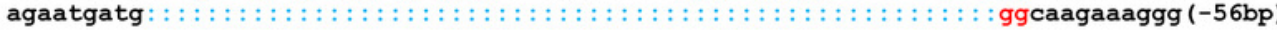

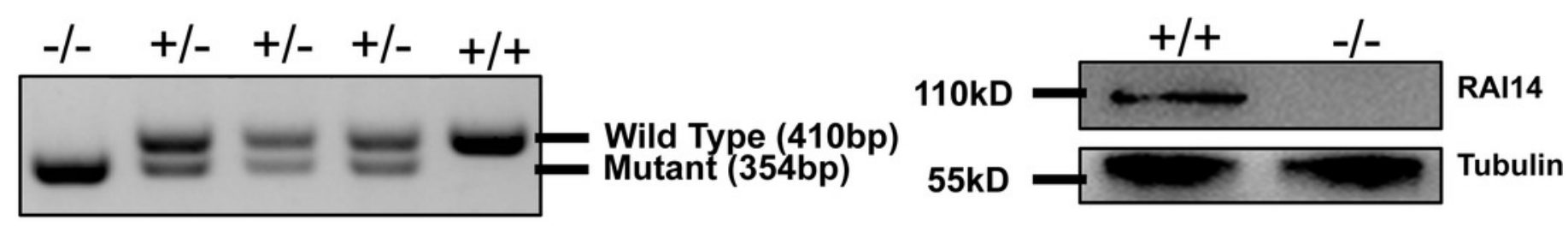

D
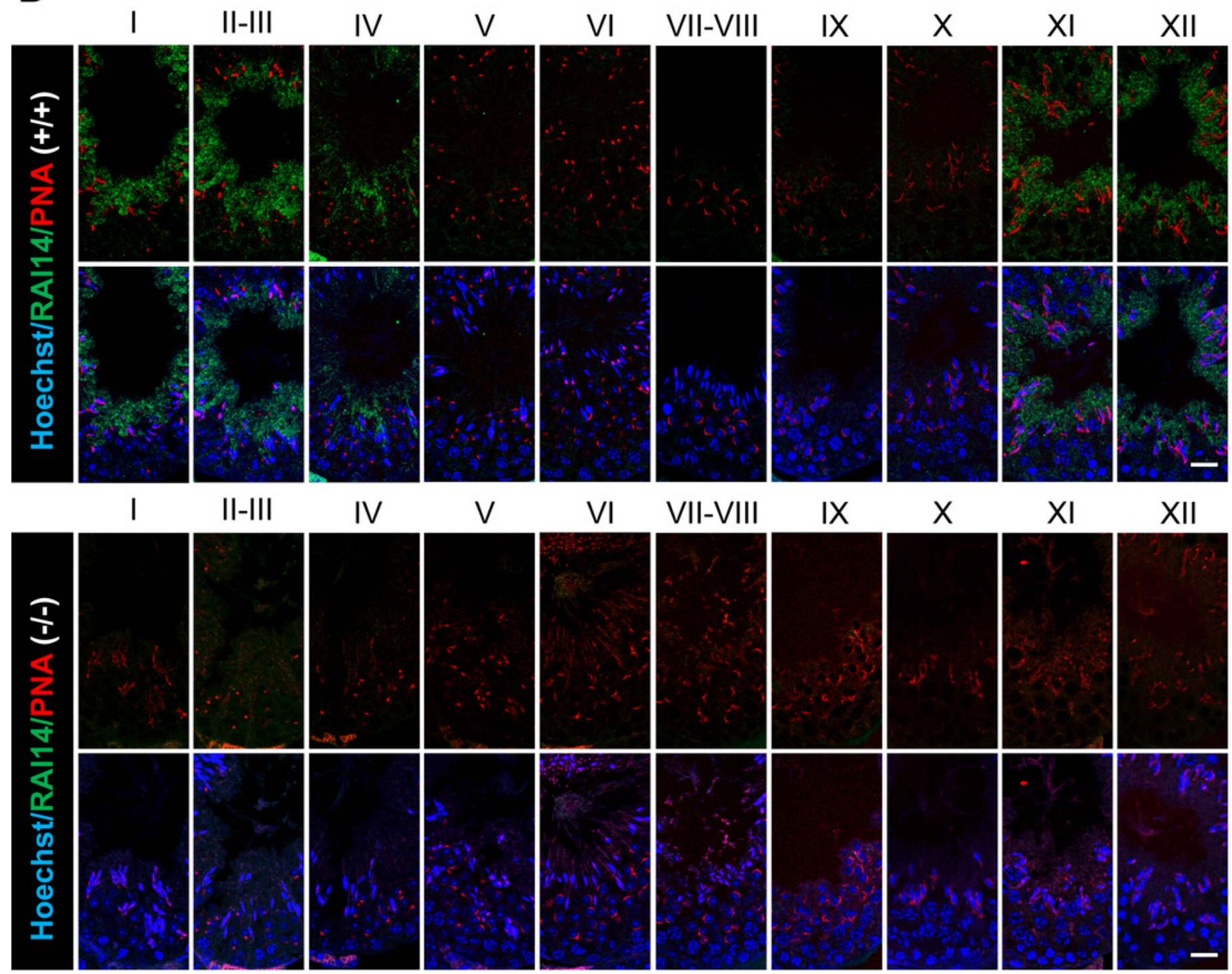


\section{Figure 2}

Rai14 ${ }^{-1}$ mice are fertile.

(A) Fertility test of Rai14 ${ }^{+/+},{ }^{--}$and ${ }^{+/}$males. For Rai14 ${ }^{+/+}, \mathrm{n}=6$; for Rai14 ${ }^{+/}, \mathrm{n}=7$, for Rai14 ', $\mathrm{n}=7, \mathrm{P}>0.05$; (B) Testes of Rai14 ${ }^{+/+}$and ${ }^{-/}$mice; (C) Testis/body weight, $\mathrm{n}=3, \mathrm{P}>0.05$;

(D) Sperm concentration in Rai14 ${ }^{+/+}$and ${ }^{*}$ mice, $\mathrm{n}=5, \mathrm{P}>0.05$; (E) Sperm motility in Rai14 ${ }^{+/ t}$ and ${ }^{-1}$ mice, $\mathrm{n}=6, \mathrm{P}>0.05$; (F) Sperm abnormality in Rai14 ${ }^{+/+}$and ${ }^{-1}$ mice, $\mathrm{n}=4, \mathrm{P}>$ 0.05; (G) HE staining of cauda epididymal sperm from Rai14 ${ }^{+/+}$and $^{-1}$ mice. Scale bar: $50 \mu \mathrm{m}$; (H) Ultrastructural analysis of cauda epididymal sperm from Rai14 ${ }^{+/+}$and ${ }^{-1}$ mice. Note the normal head and axoneme with typical " $9+2$ " microtubule structure (nine pairs of peripheral and two central microtubules, arrows) in Rai14 ${ }^{+/+}$and ${ }^{-1}$ mice. Nu, nucleus; Ac, acrosome. 
A

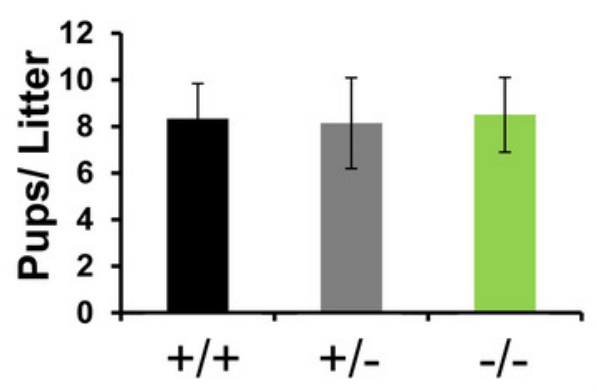

D

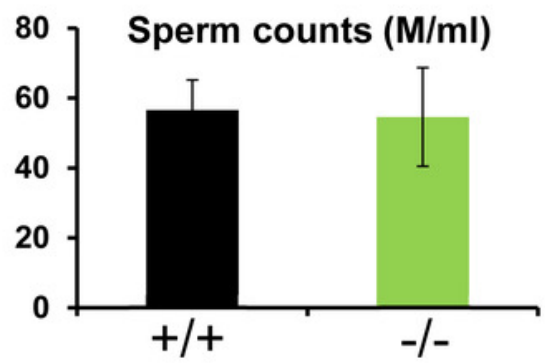

B

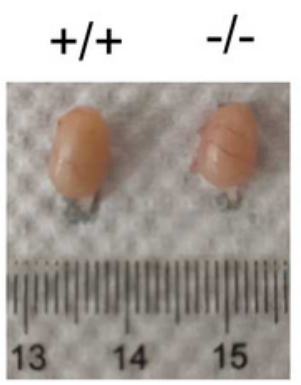

E

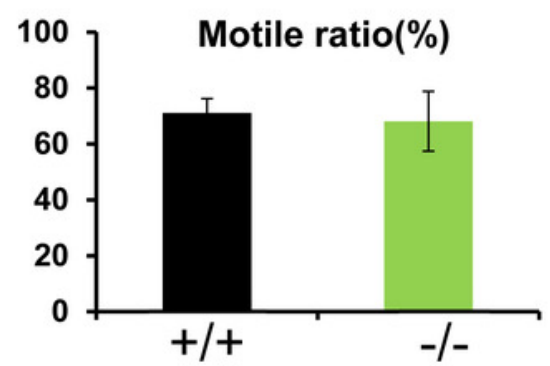

C

$F$
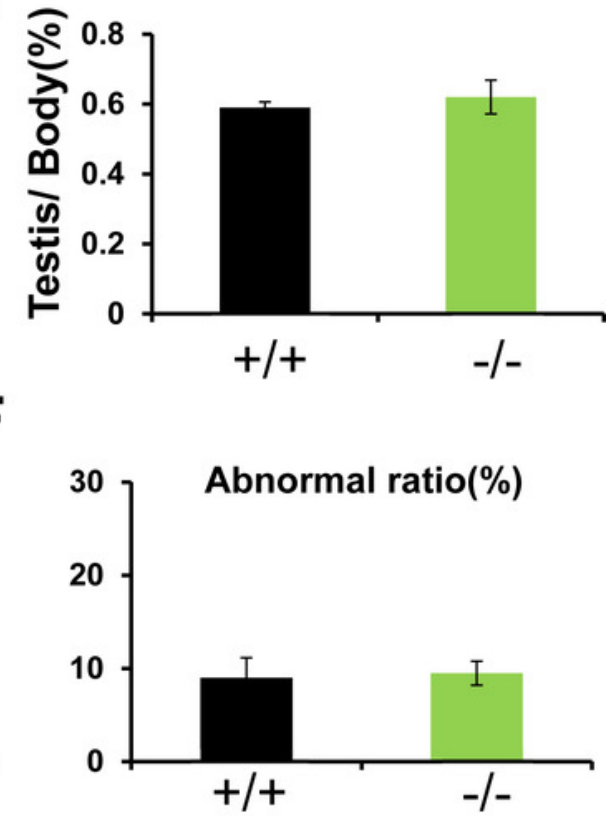
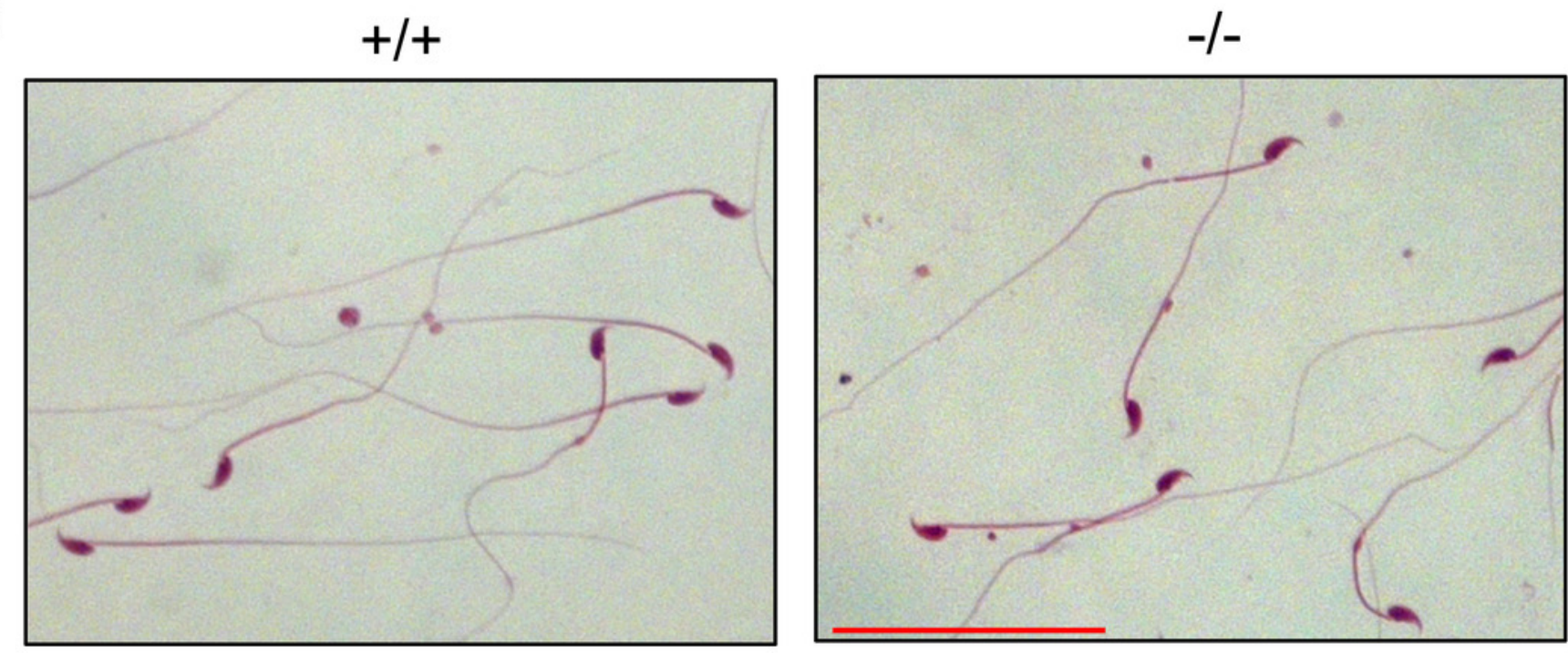

H
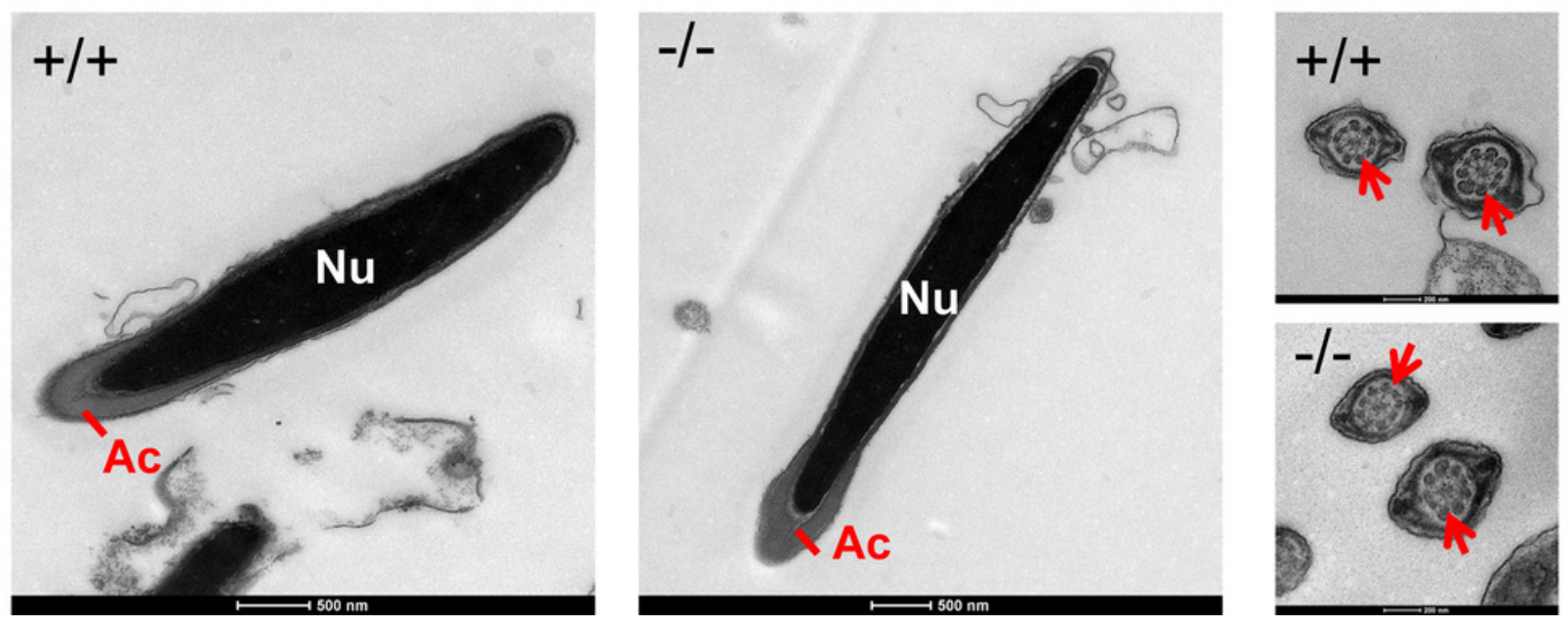


\section{Figure 3}

Normal spermatogenesis in Rai14- mice.

(A) Periodic Acid Schiff (PAS) staining of testicular sections from Rai14 ${ }^{+/ t}$ and ${ }^{-1}$ mice. The epithelial cycle is divided into 12 stages recognized by PAS, according to changes of the acrosome and nuclear morphology of spermatids. Scale bar: $20 \mu \mathrm{m}$; (B) HE staining of the cauda epididymis obtained from Rai14 ${ }^{+/+}$and ${ }^{*}$ mice. Scale bar: $100 \mu$ m; (C) Immunostaining of Lin28 from Rai14 ${ }^{+/+}$and ${ }^{*}$ testes; (D) Quantification of (C), $n=5, P>0.05$. Thirty tubules were counted per sample. Scale bar: $20 \mu \mathrm{m}$; (E) Immunostaining of $\mathrm{yH} 2 \mathrm{AX}$ from Rail4 ${ }^{+/+}$and ${ }^{*}$ testes; (F) Quantification of (E), for Rai14 ${ }^{+/+}, \mathrm{n}=5$; for Rai14 ${ }^{*}, \mathrm{n}=4$; $\mathrm{P}>0.05$. Thirty tubules were counted per sample. Scale bar: $20 \mu \mathrm{m}$; (G) Immunostaining of Vimentin from Rai14 ${ }^{+/+}$and $^{-1}$ testes; (H) Quantification of $(G), n=5, P>0.05$. Thirty tubules were counted

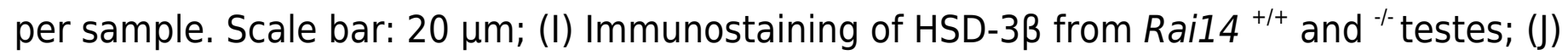
Quantification of (I), $n=3, P>0.05$. Three slides were counted per sample. Scale bar: 50 $\mu \mathrm{m}$; (K) TUNEL assay of Rai14 ${ }^{+/+}$and ${ }^{-1}$ testes; (L) Quantification of $(K), n=4, P>0.05$. Thirty tubules were counted per sample. Scale bar: $20 \mu \mathrm{m}$. 
A

$+$

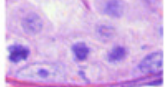
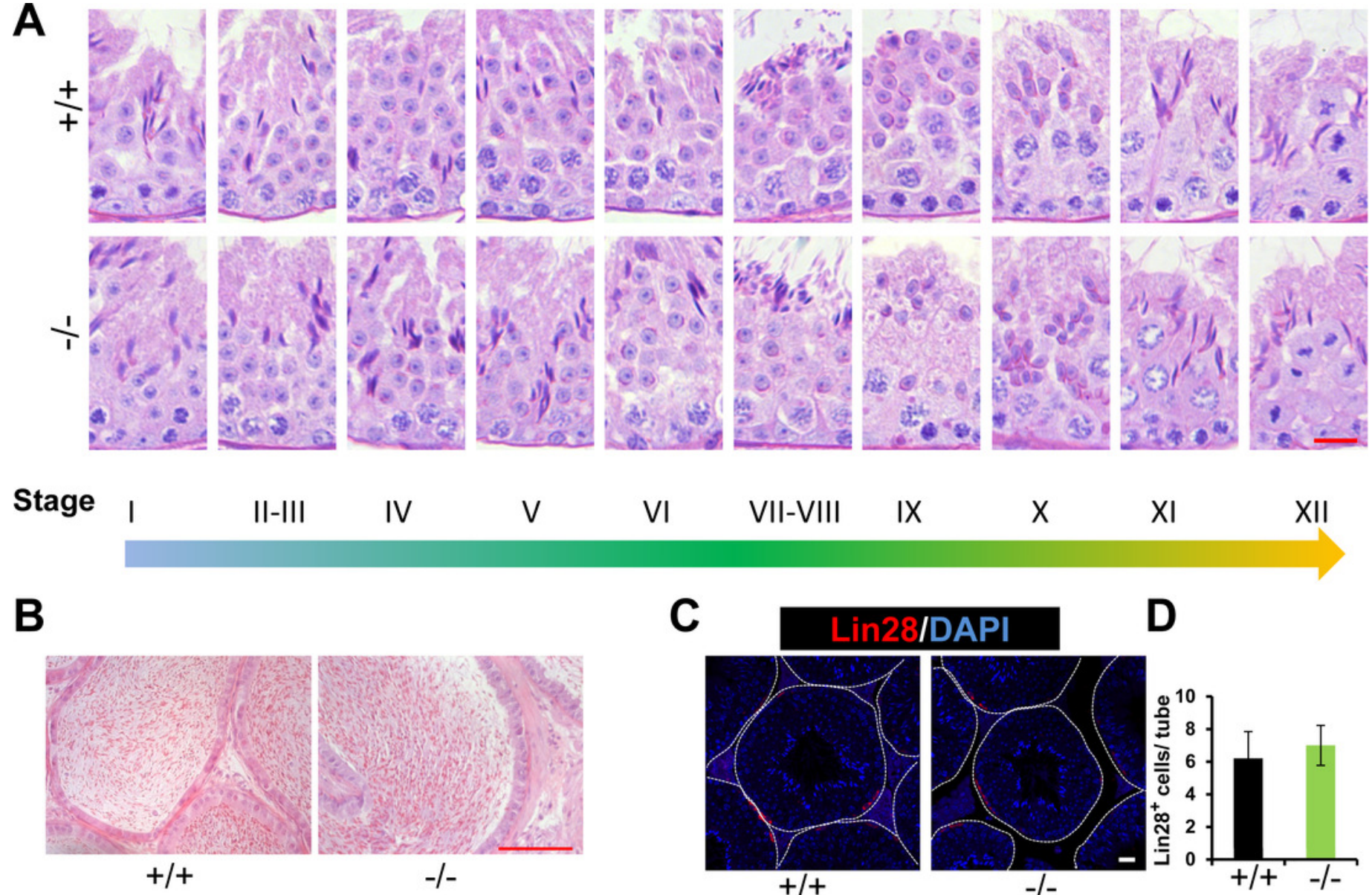

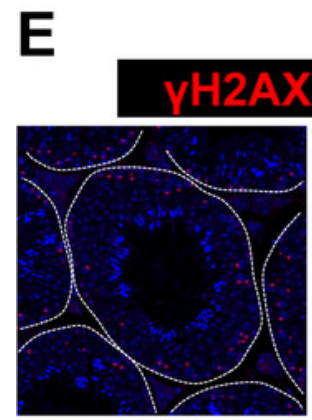

$+/+$

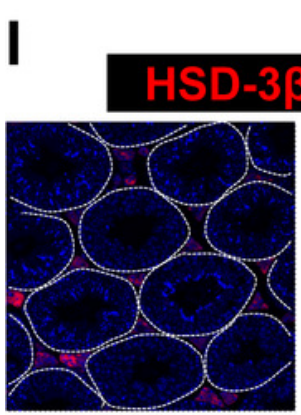

$+/+$
$\mathbf{F}$

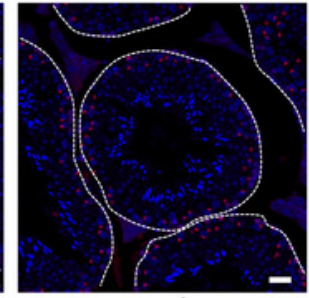

$-/-$

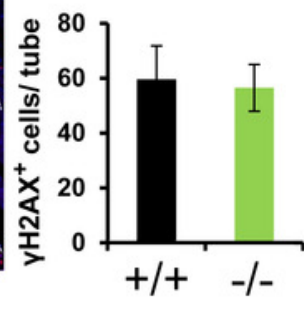

J
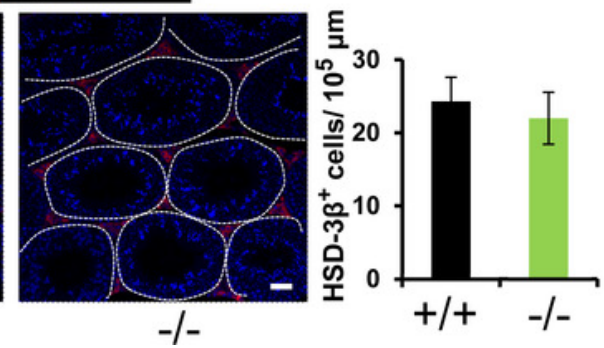

VI VII-VIII IX

$x$

XI

XII

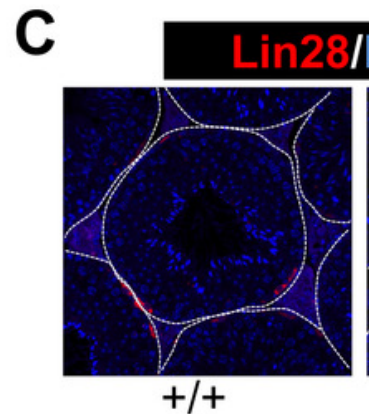

G

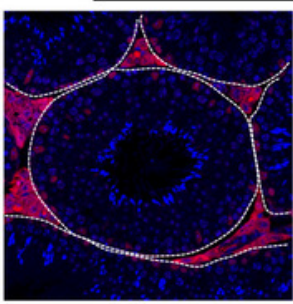

K

\section{Vimentin /DAPI}

$+/+$
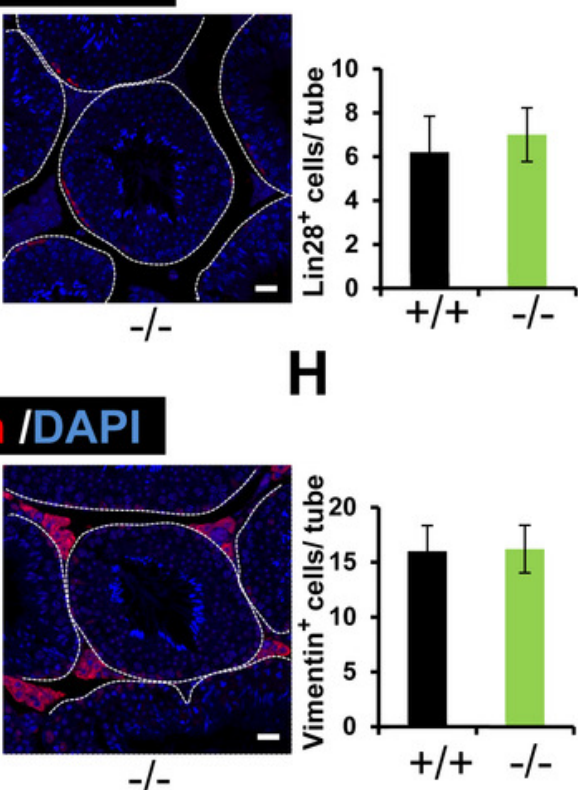

$\mathrm{H}$

$\mathbf{L}$

\section{TUNEL /DAPI}

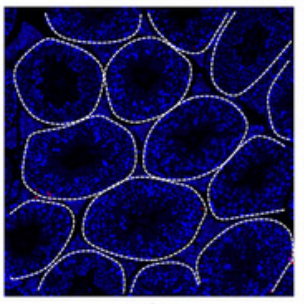

$+/+$
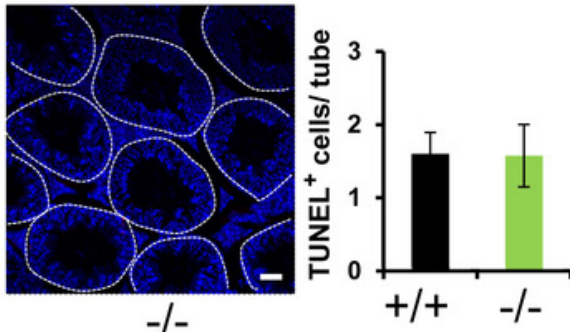
Figure 4

Expression and distribution of ES-associated genes/proteins.

Real-time quantitative PCR analysis of $\beta$-catenin (A), Espin (B) and Palladin (C) from Rai14 ${ }^{+/+}$ and $^{-1}$ testes. $n=3, P>0.05$; Immunostaining of basal ES protein $\beta$-catenin (D, E) and Espin $(\mathrm{F}, \mathrm{G})$ from Rai14 ${ }^{+/+}$and ${ }^{-1}$ testes. Scale bar: $20 \mu \mathrm{m}$; Immunostaining of apical ES protein Espin $(F, G)$ and Palladin $(\mathrm{H}, \mathrm{I})$ from Rai14 ${ }^{+/+}$and $^{-1 /}$ testes. Scale bar: $20 \mu \mathrm{m}$. 
A B C
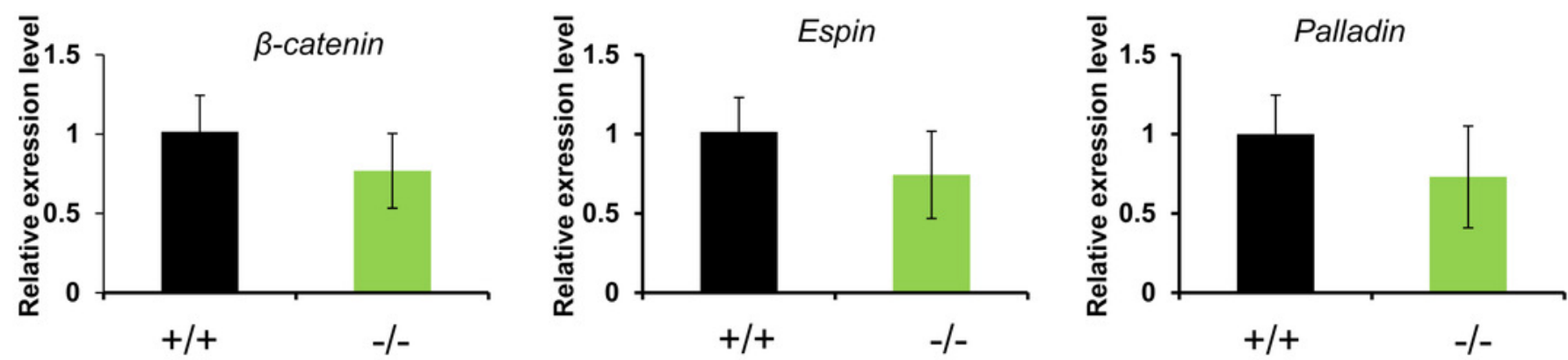

D

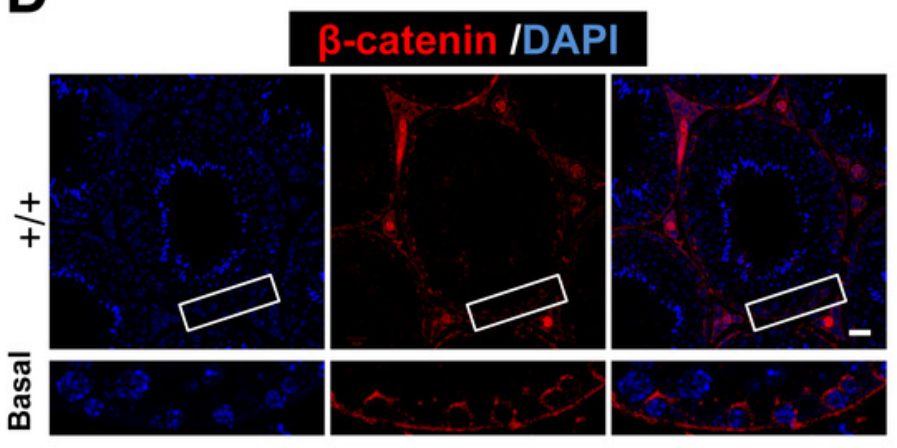

$\mathbf{F}$

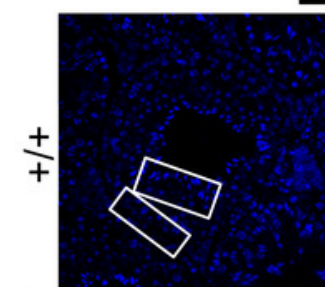

Espin /DAPI

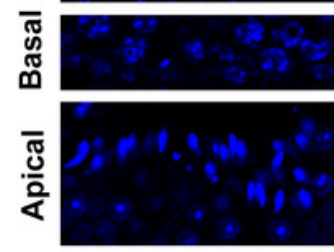

H
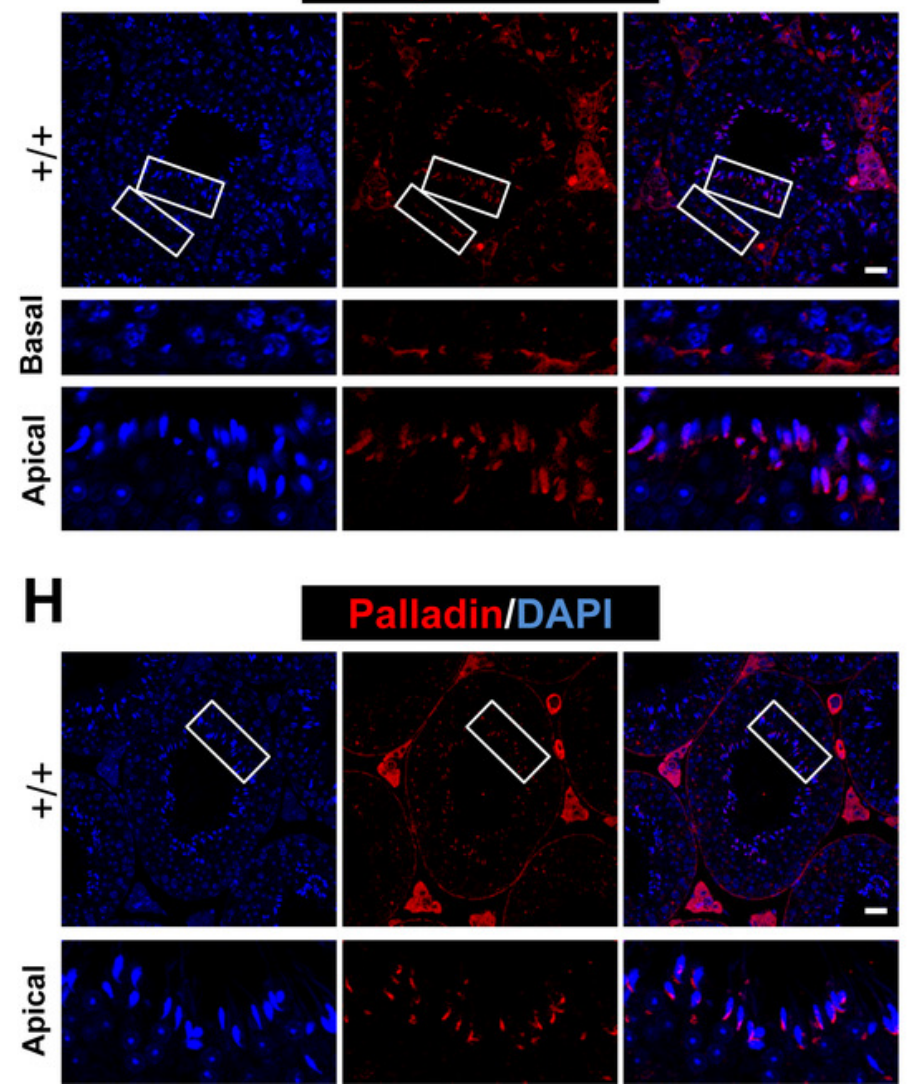

Palladin/DAPI
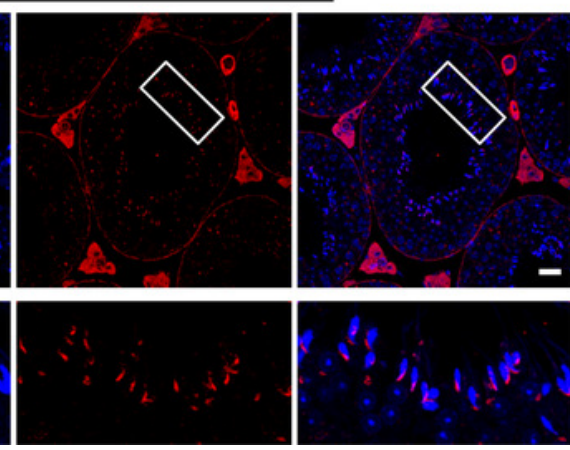

E

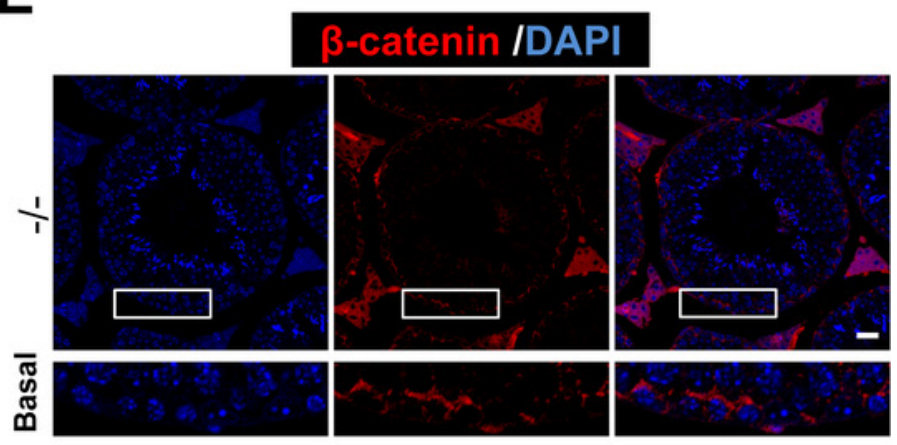

G
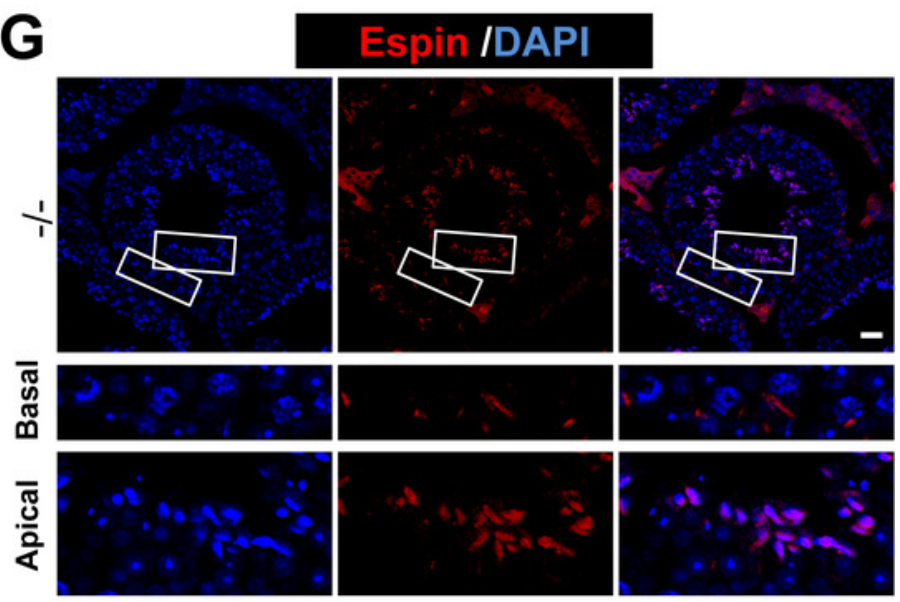

I

Palladin/DAPI

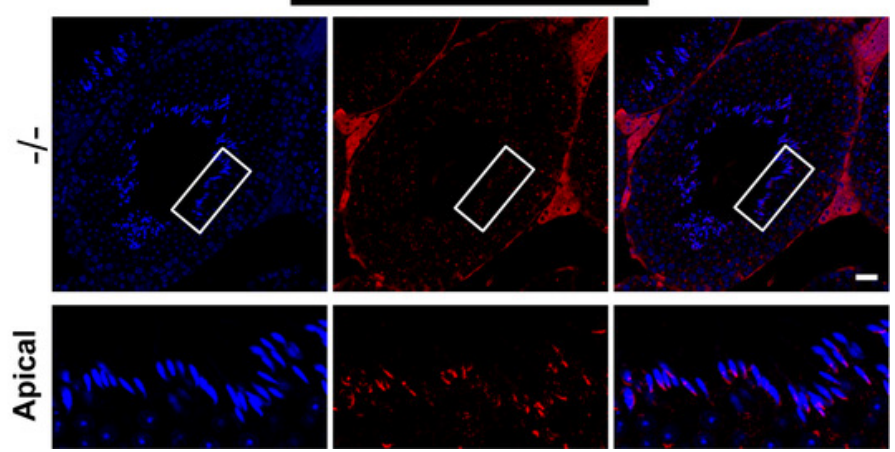




\section{Figure 5}

Rai14 is not required for F-actin organization.

(A) Phalloidin-labeled F-actin staining of Rai14 ${ }^{+/+}$and ${ }^{-1}$ spermatids at steps 13-14. Scale bar:

$20 \mu \mathrm{m}$; (B) TEM analysis of the apical ES from Rai14 ${ }^{+/+}$and ${ }^{-1}$ spermatids at steps 13-14. ES synchronously stretches along with the acrosome, and is characterized by the presence of actin filament bundles (arrows). Nu, nucleus; Ac, acrosome; ER, endoplasmic reticulum. 
A

\section{F-actin /DAPI}
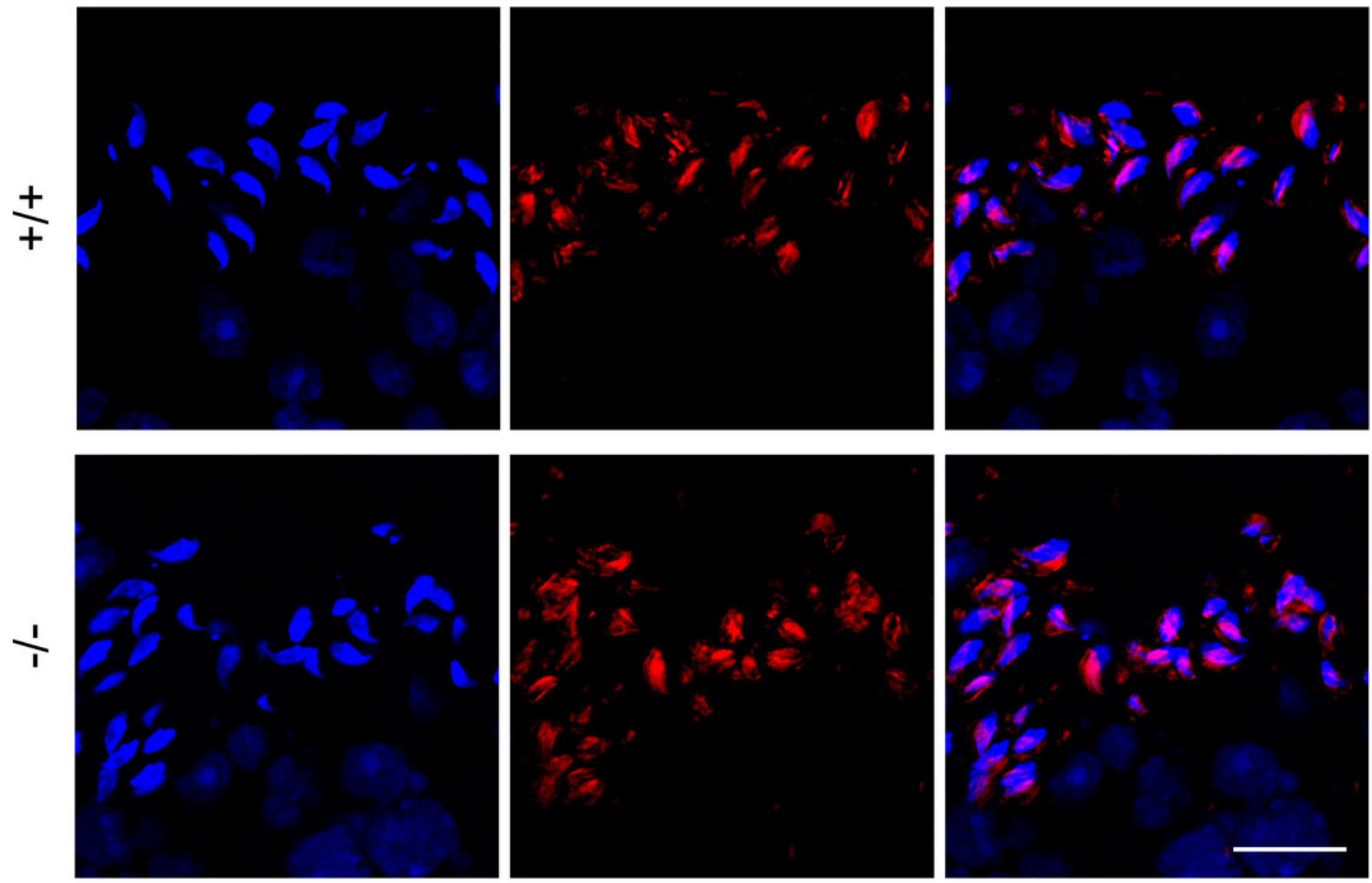

B

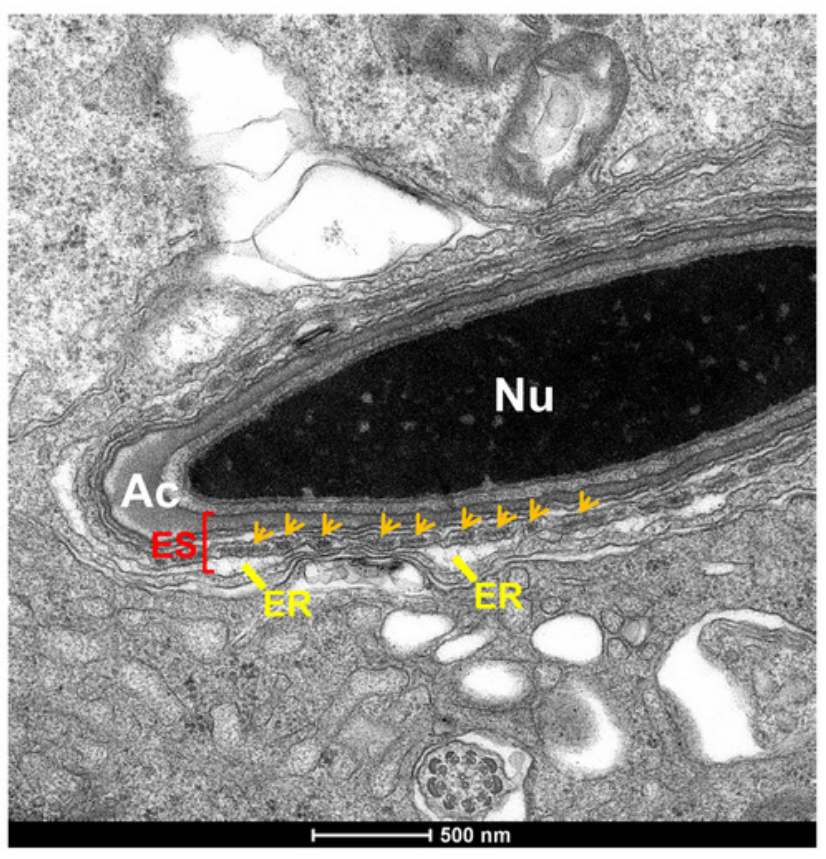

$+/+$

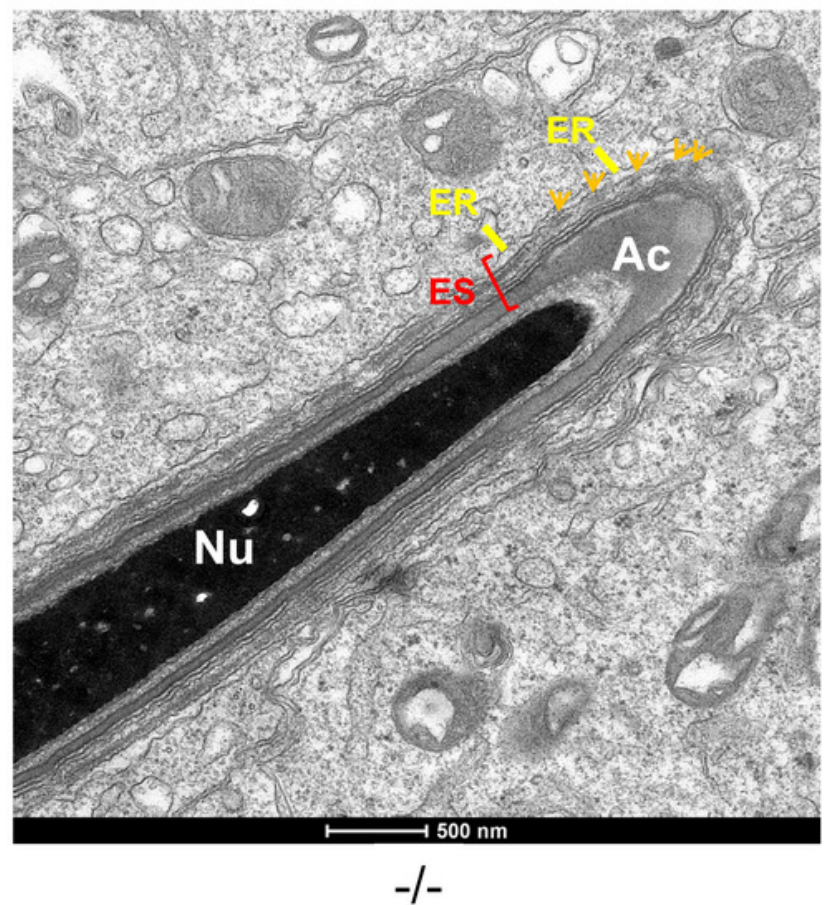

